\title{
Marcadores sociais da diferença e infância: relações de poder no contexto escolar ${ }^{*}$
}

\author{
Érica Renata de Souza"*
}

\begin{abstract}
Resumo
Na primeira parte do artigo apresento contribuições de autores de diversas áreas no que se refere às relações de gênero em sala de aula, entre crianças e adolescentes. Na segunda parte, apresento resultados parciais da pesquisa de campo de minha dissertação de Mestrado, realizada numa escola pública da cidade de Campinas, Estado de São Paulo, analisando temas como a relação das crianças com as diferenças de classe, raça, gênero e outros marcadores sociais, as hierarquias de poder na sala de aula e as concepções infantis sobre heteronormatividade.
\end{abstract}

Palavras-chave: Infância, Educação, Gênero, Sexualidade, Homossexualidade.

\footnotetext{
" Recebido para publicação em março de 2006, aprovado em maio de 2006. Este artigo é parte revisada da minha dissertação de Mestrado: Souza, Érica Renata de. Questões de Gênero na Infância e na Escola. Dissertação de Mestrado em Antropologia Social, Campinas-SP, Instituto de Filosofia e Ciências Humanas, Universidade Estadual de Campinas, 1999. Agradecimentos especiais à CAPES, à orientadora Profa. Dra. Mariza Corrêa e aos sujeitos da pesquisa.

** Professora da Pontifícia Universidade Católica de Campinas.

e_souza@uol.com.br
}

cadernos pagu (26), janeiro-junho de 2006: pp.169-199. 
Marcadores sociais da diferença e infância

\author{
Markers of Social Difference and Childhood: \\ Relationships of Power in Schooling
}

\begin{abstract}
In the first part of this article I present theorical contributions from various fields of knowledge concerning gender relations in the classroom among children and adolescents. In the second part, I present partial results from the field research conducted for my Master's dissertation, which took place in a public school in the city of Campinas, Sao Paulo State. The themes I analyze are: children's relations to differences of class, race, gender and other social markers; hierarchies of power in the classroom; and children's concepts on heternormativity.
\end{abstract}

Key Words:. Childhood, Education, Gender, Sexuality, Homosexuality. 
Érica Renata de Souza

Gênero, infância e Educação: contribuições teóricas das ciências humanas e sociais

Teorias do corpo precisam de uma abordagem de gênero, e teorias feministas sobre corpos marcados pelo gênero precisam de "uma abordagem sobre a criança". ${ }^{1}$

Segundo Sara Delamont ${ }^{2}$, defensora do uso da abordagem antropológica na área da educação ${ }^{3}$, as distinções de gênero são mantidas pela escola através da sua organização, das estratégias de controle e motivação das crianças, da organização e conteúdo das lições, das conversas informais entre alunos e professores $e$ das atividades estereotipadas das crianças. No entanto, a autora não concebe a escola como a única instituição responsável pelas distinções de gênero, argumentando que, ao chegar à escola, garotos e garotas já têm noção do que devem ser seus respectivos "comportamentos apropriados". Através da linguagem, a criança aprende a "comportar-se apropriadamente" como garoto ou garota; as conversas em sala de aula (aliadas aos componentes não-verbais) são apenas um dos meios de estruturação das relações de desigualdades, as quais, muitas vezes, foram estabelecidas em outros contextos (fora da escola e também através da linguagem não-verbal), sendo apenas reconstruídas ou sustentadas em sala de aula.

A linguagem, para a autora, é uma forma de prática social que incorpora e sustenta valores, inclusive aqueles que estipulam o "ser" "masculino" ou "feminina" numa determinada cultura, $e$ que, por sua vez, também podem ser usada em prol de mudanças,

1 MARTIN, Karin A. Becoming a gendered body: practices of preschools. American Sociological Review, vol. 63, n 4, aug./1998, pp.494-511: "Theories of the body need gendering, and feminist theories of gendered bodies need "childrening'". [Todas as traduções são livres.]

2 Citada por Swann, Joan. Girls, boys and language. Oxford, Backwell, 1992.

3 ANDRÉ, Marli. E.D.A. Etnografia da prática escolar. Campinas, Papirus, 1995. 
Marcadores sociais da diferença e infância

visando à igualdade entre os gêneros. Nesse sentido, a criança constrói um "sistema interno de regras de gênero" a partir de sua experiência e das representações disponíveis na cultura em que está inserida. Através da linguagem escrita e falada e das imagens lingüísticas e não-lingüísticas com as quais interage, a criança aprende as expectativas para seu comportamento. Contudo, a autora não sugere que a criança seja um recipiente passivo de mensagens sociais, determinada pelas estruturas da linguagem, mas argumenta que "as crianças estão também (re)negociando relações com outros $e$ (re)interpretando as imagens que encontram". 4

Quando chegam à escola, meninas e meninos já começaram a aprender a linguagem diferenciada de gênero; começaram a aprender como falar diferentemente como uma menina ou um menino, como falar com outras meninas e meninos, e como falar sobre elas/eles. Esta aprendizagem continua através dos anos escolares $e$ posteriormente. ${ }^{5}$

Swann, portanto, mostra que a linguagem opera em vários níveis. O social é incorporado na linguagem, organizado conceitualmente, na relação da criança com as expectativas sociais de gênero sobre ela, na relação com as outras crianças $e$ as diferenças demarcadas de gênero entre elas e, portanto, na construção do binarismo dos gêneros opostos, onde a corporificação das diferenças permite a visibilidade de um "outro".

\footnotetext{
4 SwANN, J. Girls, boys and language. Op. cit., p.11: "children are also (re)negotiating relationships with others and (re)interpreting the images they encounter".

${ }^{5}$ ID., IB., p.14: "By the time they come to school, girls and boys have already begun to learn gender-differentiated language; they have begun to learn how to speak differently as a girl or a boy, how to speak to other girls and boys, and how to speak about them. Such learning continues throughout the school years and afterwards".
} 
Mas, para Swann, se os sujeitos recriam ou não o estereótipo é uma questão que só tem resposta contextualmente, nos sujeitos envolvidos na interação social e na maneira como estes percebem os propósitos da interação, já que nem as palavras nem os sentidos são fixos. Os enunciadores utilizam as palavras a fim de causar efeitos específicos em contextos particulares, enquanto os receptores levam em conta uma gama de fatores ao interpretarem a informação que recebem: o contexto físico, quem é o enunciador, sua relação com ele e as intenções percebidas.

As diferenças na disponibilidade $e$ uso dos epítetos "marcados pelo gênero" também sugerem que meninas $e$ meninos estão usando a linguagem para estabelecer suas respectivas identidades de gênero e para categorizar os outros, para se acomodar em tais categorias ou para resistilas. ${ }^{6}$

Segundo Swann, os comportamentos dos gêneros variam contextualmente, onde outros marcadores como etnicidade $e$ classe social interferem. Por outro lado, ao mesmo tempo em que Swann apresenta a interação como o lugar de reinterpretação, negando que a criança seja um recipiente passivo de informações, sugere essa mesma interação como a mantenedora da dominação masculina através da naturalização das tipificações de gênero, onde as garotas (e os professores $e$ as professoras) aparecem como subordinadas e cúmplices do modo de pensar falocêntrico. Ou seja, Swann apresenta, de forma ambígua, a interação como a $\mathrm{im} /$ possibilidade de ação (agency) para as garotas.

Por outro lado, Swann salienta aspectos importantes da relação gênero e linguagem na escola, como os estereótipos

${ }^{6}$ ID., IB., p.46: "Differences in the availability and use of 'gendered' epithets also suggest that girls and boys are using language to establish their respective gender identities and to categorize others, to acquiesce in such categorization or to resist to it." 
Marcadores sociais da diferença e infância

veiculados pelos livros didáticos ${ }^{7}$, que geralmente apresentam a mulher como "incompetente" como cientistas ou em profissões legitimadas como de domínio dos homens, além da associação das mulheres como mais emocionais e menos dotadas de força física. Nesse sentido, sugere ainda o estereótipo que classifica os atos de ler e escrever como atividades "passivas" $e$, conseqüentemente, femininas, fornecendo subsídios para o sucesso escolar das meninas nas séries inicias. Comenta ainda sobre o background diferencial de gênero com o qual a criança já chega na escola e que orienta diferencialmente as escolhas de tipos de leituras com diferentes mensagens, que influenciam, na pauta da diferença e da desigualdade, o comportamento e o modo de pensar das crianças. A autora sugere também a influência das imagens veiculadas pela mídia e pelas propagandas, cujos significados são dados na inter-relação entre os componentes verbais e visuais, de acordo com as estruturas de referência da criança, dentro da cultura na qual está inserida.

Tematizando linguagem, gênero e sala de aula, ainda temos o trabalho de Nilan. ${ }^{8}$ Assim como Swann, Nilan também está preocupada com o fenômeno da interação. Numa perspectiva

7 Sobre as ilustrações dos livros didáticos, Miguel Vale de Almeida sugere, nas representações da família, um complexo de relações onde são "explícitas as hierarquias, quer através do corpo (o homem mais alto que a mulher), quer etário e de género (o filho é sempre mais alto e mais velho que a filha, e a criança mais velha é sempre um rapaz, facto este transmitido pelo texto)" (p.258). Mauro Almeida ainda sugere que nessas representações de família em que "(o) pai trabalha num escritório; a mãe trabalha em casa, onde é ajudada pela filha - que assim exercita-se nas lides domésticas -, enquanto os meninos jogam bola" (p.15), os personagens são sempre brancos. ALMEIDA, Miguel Vale de. Leitura de um livro de leitura: a sociedade contada às crianças e lembrada ao povo. In: O’NEILL, Brian J. e BRITO, Joaquim P. (orgs.) Lugares de Aqui: actas do seminário "Terrenos Portugueses". Lisboa, Publicações Dom Quixote, 1991; AlmeidA, Mauro W. B. O racismo nos livros didáticos. In: SILVA, Aracy L., GruPiOnI, Luís D. B. (orgs.) A questão indígena na sala de aula: subsídios para professores de $1^{\circ}$ e $2^{\circ}$ graus. $2^{a}$.ed. São Paulo, Brasiliense, 1993.

8 NILAN, Pam. Negotiating gendered identity in classroom disputes and collaboration. Discourse \& Society, vol.6, n 1, 1995, pp.27-47. 
da pedagogia feminista, Nilan enfoca as performances de masculinidade e feminilidade entre adolescentes australianos de distintas classes sociais, no ensino secundário. Segundo Nilan, muitos trabalhos (como o de Swann) têm tematizado as relações de manutenção das desigualdades em sala de aula por meninos, meninas e professores, numa analogia homens dominam mulheres e garotos dominam garotas na realização das tarefas, onde os professores e professoras colaborariam oferecendo mais atenção aos garotos e sugerindo desvantagens para as meninas no aprendizado de áreas como matemática e ciências, tidas como pertencentes ao domínio masculino para o grupo pesquisado. Nilan, no entanto, considera que, para a compreensão de como as relações de gênero operam contextualmente, os garotos, o que dizem e o que fazem, são elementos que também devem ser cuidadosamente considerados, remetendo à proposta de Scott sobre o estudo do gênero como o estudo das relações entre homens e mulheres. ${ }^{9}$

Para Nilan, as garotas não são vítimas passivas da agressão dos meninos ou da negligência dos professores, mas agentes na construção de si mesmas como portadoras de uma "identidade feminina" (o que não difere muito da perspectiva de Swann, a partir da qual as garotas são "cúmplices" nas distinções de gênero operantes na interação), enquanto os garotos estão mais preocupados em estabelecer sua masculinidade aos olhos dos outros garotos assim como em estabelecer sua superioridade sobre as meninas. A autora considera ainda que muitas crianças não correspondem aos estereótipos de gênero, já que a construção social da identidade é complicada por outros fatores como classe social, raça e etnicidade. A autora, no entanto, restringe este estudo às relações de gênero e classe: "A distinção entre meninas

9 ScotT, J.W. Gender and the politics of history. New York, Columbia Univ. Press, 1988. 
Marcadores sociais da diferença e infância

$e$ meninos da classe trabalhadora e meninas e meninos da classe dominante é uma distinção profunda, e não superficial". ${ }^{10}$

Nesse sentido, a autora sugere que as performances acadêmicas variam de acordo com as distintas classes sociais ${ }^{11} e$ que questões de gênero e classe são ambas essenciais ao funcionamento do sistema escolar, principalmente quando este exige que os estudantes consumam e produzam textos que expressem tipos específicos de conhecimento intelectual, ou seja, que expressem o seu capital cultural.

Focalizemos agora o corpo e o gênero na primeira infância. A socióloga Karin Martin ${ }^{12}$ observou cinco classes de educação infantil, com crianças de três a cinco anos, pertencentes à classe média. A autora sugere a existência de um "currículo oculto" (hidden curriculum) $)^{13}$ que transforma crianças que apresentam movimentos similares do corpo em "garotos" e "garotas", ou seja, em crianças cujas práticas do corpo diferem. Esse "currículo oculto", além de criar as diferenças entre gêneros e facilitar o processo já iniciado na família, faz com que tais diferenças apareçam e sejam sentidas como "naturais".

Segundo a autora, "geralmente os corpos das mulheres são confinados, seus movimentos, restringidos" ${ }^{14}$, exemplificando: as mulheres dão passos menores que os homens, sentam em

\footnotetext{
${ }^{10}$ NiLAN, P. Negotiating gendered... Op. cit., p.28.

${ }^{11}$ Neste sentido, ver também, Bourdieu, Pierre e PASSERON, Jean Claude. A reprodução: elementos para uma teoria do sistema de ensino. Rio de Janeiro, Francisco Alves, 1982; BouRdiEU, Pierre. A escola conservadora: as desigualdades frente à escola e à cultura. In: NogUEIRA, Maria Alice e CATANI, Afrânio. (orgs.) Pierre Bourdieu: escritos de educação. Petrópolis, Vozes, 1998.

${ }^{12}$ MARTIN, K. A. Becoming a gendered body... Op. cit.

${ }^{13}$ Conceito corrente nas teorias educacionais. Ver também em BRITZMAN, Deborah P. O que é esta coisa chamada amor: identidade homossexual, educação e currículo. Educação \& Realidade, vol. 21, n 1, jan./jun. de 1996, pp.71-96.

${ }^{14}$ MARTIN, K. A. Becoming a gendered body... Op. cit., p.494: "Generally, women's bodies are confined, their movements restricted".
} 
posições "fechadas", ocupam menos espaço físico... A autora considera que tais diferenças podem ser notadas desde a primeira infância, mas que também são atravessadas por diferenças de raça, classe, sexualidade e de tipo e tamanho do corpo. Os corpos, marcados pelo gênero, pela raça e pela classe, criam contextos particulares para relaçóes sociais à medida em que assinalam e negociam informações sobre status e poder. Nesse sentido, os corpos claramente "delineados" pelo gênero favorecem a manutenção da hierarquia. Para Martin, o corpo é um lugar do gênero, "corpos controlados, adornados, estilizados, apropriadamente comportados e em movimento estabelecem o gênero e as relações de gênero". ${ }^{15}$

Esse movimento é o que constitui a concepção de performance de gênero para Martin. Além disso, sugere também que o gênero seja incorporado psíquica e fisicamente, citando Robert Connell ${ }^{16}$, para quem o gênero se corporifica através de posturas, musculatura e tensões do corpo. Se para Connel o corpo é o lugar onde o poder masculino se reconhece, Young ${ }^{17}$ sugere que

a falta de confiança $e$ ação das mulheres estão corporificadas e se originam de uma falta de habilidade para se movimentarem com confiança no espaço, para ocupar o espaço, para usar o corpo na sua mais completa extensão. ${ }^{18}$

Nesse sentido, o "currículo oculto" é marcado pelo gênero $e$, através do controle das práticas do corpo, colabora para a

\footnotetext{
${ }^{15}$ ID., IB., p.495: "managed, adorned, fashioned, properly comported and moving bodies establish gender and gender relations" (idem, ibidem, p.495).

${ }^{16}$ Citado por MARTIN, K. A. Becoming a gendered body... Op. cit.

${ }^{17}$ ID., IB.

${ }^{18}$ ID., IB., p.495: "women's lack of confidence and agency are embodied and stem from an inability to move confidently in space, to take up space, to use one's body to its fullest extent."
} 
Marcadores sociais da diferença e infância

corporificação de gênero na infância, sob a aparência da naturalidade.

Gênero, infância e educação: uma experiência na escola pública

Vejamos agora em que medida essas "evidências" sugeridas ou percebidas por nossos autores e outras foram (ou não) encontradas nas relações entre as crianças, tanto numa classe de aceleração ${ }^{19}$ quanto numa $4^{\text {a }}$ série regular, observadas durante minha pesquisa, realizada em $1998^{20}$, numa escola pública da cidade de Campinas, Estado de São Paulo, localizada num bairro de classe média. Contudo, por se localizar numa avenida de fácil acesso a várias linhas de ônibus a escola recebe alunos de diversos bairros e até mesmo de pequenos municípios vizinhos. Dessa forma, há uma grande heterogeneidade em relação ao local de residência das crianças.

Apenas uma minoria dos alunos da classe de aceleração observada, composta por três alunos, habitava em bairros estigmatizados pelo alto índice de criminalidade, fato que parece fragilizar o discurso das professoras, o qual responsabilizava "o meio" onde as crianças viviam por seus comportamentos "desviantes": agressivos, desinteressados, "sem-educação", etc. Essa minoria, no entanto, parecia ser utilizada "como evidência

\footnotetext{
${ }^{19}$ Bussab, S. Apresentação. In: Tozzi, D. A. e OnESTI, L. F. (coords.) Os desafios enfrentados no cotidiano escolar. São Paulo, FDE, 1997, p.3: "Basicamente, este Projeto visa eliminar a defasagem entre série e idade regular de matrícula, do Ciclo Básico à $4^{\mathrm{a}}$. série, criando condições para que os alunos avancem em seu percurso escolar, passando a cursar uma série mais compatível com sua idade."

${ }^{20}$ Cabe ressaltar que as leituras dos trabalhos citados foram realizadas ao longo dos dois anos e meio de duração do Mestrado. Quero dizer que não fui a campo com "categorias prontas", "testar" tais teorias, mas que houve uma articulação processual entre as contribuições teóricas e os dados empíricos.
} 
ideológica do desvio geral da turma". ${ }^{21}$ Essa estigmatização era encontrada, inclusive, no discurso das próprias crianças.

A classe de aceleração, segundo as próprias professoras, apresentava um currículo correspondente aos conteúdos didáticos de uma $4^{\mathrm{a}}$ série, com algumas "adaptações". De acordo com a diretoria $e$ as professoras, essa adaptação fazia-se necessária porque não estavam trabalhando com crianças nas classes de aceleração, mas com "pré-adolescentes". Essa terminologia era utilizada pelo discurso legitimador dessas classes como mais um elemento distintivo, que "diferenciava" o aluno da aceleração, o "grande", dos demais, alunos de $1^{\text {a }}$ à $4^{\text {a }}$ série, os "pequenos". "Pequenos" e "grandes" também se apresentavam como categorias nativas, apropriadas tanto pelos professores $e$ pela diretora, quanto pelas crianças, e correspondiam, respectivamente, às "crianças" e aos "pré-adolescentes". No entanto, na hierarquia da escola, o status de "grande" não era nenhuma vantagem. Ser "grande" era sinônimo de ser repetente, de pertencer à "escória" que constituía a classe de aceleração e de ser sempre o responsável por qualquer problema que pudesse aparecer numa relação qualquer entre um "grande" $e$ um "pequeno". A idade dos alunos da classe de aceleração variava entre 11 e 14 anos. A classe comportava 16 meninos e 7 meninas repetentes, corroborando a sugestão de Swann ${ }^{22}$ de que o sistema favorece o sucesso escolar das meninas nas séries iniciais.

A $4^{a}$ série era uma classe que comportava crianças "em fase" com o currículo e o programa de ensino definido pelo sistema público estadual, na faixa dos 10 anos, não-repetentes. $\mathrm{Ou}$, ainda, crianças que repetiram uma série qualquer, mas não encontraram vaga na classe de aceleração. Segundo a diretora, existia um tipo de filtragem para selecionar os alunos que

${ }^{21}$ SCHNEIDER, D. "Alunos excepcionais": um estudo de caso de desvio. In: Velho, G. (org.) Desvio e divergência: uma crítica da patologia social. Rio de Janeiro, Zahar, 1971, p.74.

22 SwANN, J. Girls, boys and language. Op. cit. 
Marcadores sociais da diferença e infância

"realmente" precisavam estar incluídos em uma das vinte vagas limitadas que cada classe de aceleração oferecia, ou seja, os alunos que mais apresentavam "problemas".

\section{A relação das crianças com os marcadores sociais}

Na classe de aceleração, sugiro que a noção de estética está associada à beleza segundo o padrão branco ocidental; por isso, estreitamente vinculada à questão da raça. "Negão", "preto" e "carvão" são alguns dos epítetos utilizados por Mauro e Luís para se referirem a Guilherme. Numa ocasião, Mauro dirigiu-se a Ana, comentando sobre o cabelo da garota negra: "Tirou pra lavar? Senão vai enferrujar!", além de, assim como Wellington, chamá-la de "Bombril", "Ferrugem" ou "Cabelo de Vassoura". Em outro momento, um grupo de crianças ridicularizava o cabelo volumoso de um garoto, classificando-o como uma "mata", enquanto outro chamava Ana de "canhão". ${ }^{23}$ Marcelo chama Felipe, negro, de "macaco" e imita o animal. Ricardo ainda costuma se referir a Luís como "Buiú" ou "Fedor". Frankenberg ${ }^{24}$ situa o problema:

Assim como as vidas de homens e mulheres são moldados por seu gênero, e a experiência no mundo tanto de mulheres heterossexuais quanto lésbicas são marcadas por sua sexualidade, pessoas brancas e pessoas de cor vivem vidas racialmente estruturadas. ${ }^{25}$

\footnotetext{
${ }^{23}$ Gíria que quer dizer mulher feia.

${ }^{24}$ FRANKENBERG, Ruth. Growing up white: feminism, racism and the social geography of childhood. In: MCDOWELL, Linda e SHARP, Joanne P. (eds.) Space, gender, knowledge: feminist readings. London, Arnold, 1997.

${ }^{25}$ ID., IB., p.209: “Just as both men's and women's lives are shaped by their gender, and both heterosexual and lesbian women's experiences in the world are marked by their sexuality, white people and people of colour live racially structured lives."
} 
Num discurso semelhante ao de Scott ${ }^{26}$, Frankenberg sugere a raça como uma categoria não reduzível a explicações biológicas, construída e alterada histórica e politicamente. ${ }^{27}$ Dessa forma, assim como a negritude, a branquitude (whiteness) é um conceito que hoje ganha três formas: a vantagem de uma posição estrutural privilegiada em termos sociais como longevitude, menores chances de pobreza, acesso mais fácil à saúde, etc. (embora não ignore outros marcadores favorecendo esses privilégios, como sexualidade, idade, classe, etc.), um ponto de vista a partir do qual se olha os outros e a sociedade ("o lugar de onde alguém fala", para $\operatorname{Orlandi}^{28}$ ) e a "bagagem" de um conjunto de práticas culturais vistas como "normais". Sugiro que, particularmente no Brasil, esses "privilégios" citados pela autora constituem mais uma questão de classe do que de raça, embora saibamos que raça $e$ classe são marcadores interdependentes. Mas é interessante pensarmos a raça corporificada enquanto perspectiva e bagagem cultural, além de marcar os próprios corpos, lugar onde vai se defrontar/confrontar com a questão da estética. Se a cultura racista dominante é reproduzida pelos brancos ${ }^{29}$, a beleza branca é a dominante, a "ideal", assim como as práticas culturais e o ponto de vista do branco ocidental. No entanto, essa marca no corpo não opera sozinha, como lembram os teóricos da corporificação (embodiment) ao rejeitarem a dicotomia corpo-mente..$^{30} \mathrm{~A}$

\footnotetext{
${ }^{26}$ ScOTT, J.W. Gender and the politics of history. Op. cit.

${ }^{27}$ Ver também STOLCKE, Verena. Sexo está para gênero assim como raça para etnicidade? Estudos Afro-Asiáticos, n 20, 1991, p.109: a autora sugere que "(o)nde quer que se empregue 'raça' como indicador de diferença $e$ desigualdades sociais estamos lidando - não menos que no caso de etnicidade com uma construção sócio-histórica."

${ }^{28}$ OrLandi, Eni P. A linguagem e seu funcionamento: as formas do discurso. Campinas, Pontes, 1987.

${ }^{29}$ FRANKENBERG, R. Growing up white... Op. cit.

${ }^{30}$ StRATHERn, Andrew J. Body thoughts. Ann Arbor, The University of Michigan Press, 1996; CSORDAS, Thomas J. Introduction: the body as representation and being-in-the-world. In: CSORDAS, T. J. (ed.) Embodiment and experience: the
} 
Marcadores sociais da diferença e infância

corporificação é experiência percebida e incorporada, física $e$ simbólica, prática e representação. Pensando na noção de corporificação, poderíamos dizer que a raça é a percepção que termina no corpo e que é, a priori, ponto de vista, julgamento moral e inserção em experiências e práticas culturais específicas.

Mauro e Ana são as principais personagens dos conflitos raciais na classe de aceleração. Neste caso, a matriz heterossexual ${ }^{31}$ não pode ser exclusivamente apontada como responsável. Mauro e Ana não se apresentam apenas como os opostos complementares inteligíveis pela matriz heterossexual enquanto homem $e$ mulher, mas representam o conflito entre raças, padrões estéticos, classes sociais e capitais culturais distintos. Se para Bourdieu o capital cultural está atrelado à questão da classe e para Frankenberg os privilégios sociais estão diretamente associados à raça, penso que o capital cultural, enquanto "bagagem" cultural, também estaria ligado à raça, como também sugere Britzman:

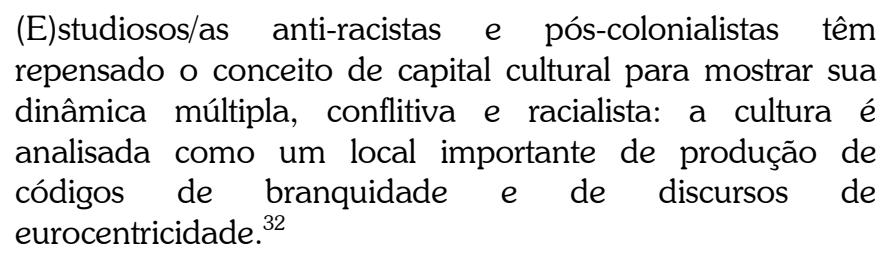

(E)studiosos/as anti-racistas e pós-colonialistas têm repensado o conceito de capital cultural para mostrar sua dinâmica múltipla, conflitiva e racialista: a cultura é analisada como um local importante de produção de códigos de branquidade $e$ de discursos de eurocentricidade. ${ }^{32}$

Pensando em Ana, menina negra e pobre, e Mauro, garoto branco e pertencente à classe média, ou seja, nas suas díspares posições na estrutura em termos de raça, classe, capital cultural e gênero, fica impossível tentarmos detectar causas e conseqüencias entre os marcadores sociais. Ana e Mauro são exemplos de

existencial ground of culture and self. Cambridge, Cambrige University Press, 1996 [1994].

${ }^{31}$ ButLen, J. Gender Trouble: Feminism and the subversion of identity. New York, Routledge, 1990.

32 BRITZMAN, D. P. O que é esta coisa chamada amor... Op. cit., p.72. 
pertencimento a configurações sociais distintas e particulares, que não podem ser reduzidas a "uma questão de raça", de classe ou de gênero. Situando essas crianças no contexto escolar, temos percepções de classe, raça, gênero, sexualidade e estética inseridas nas relações de um sistema que, segundo Bourdieu ${ }^{33}$, apesar do discurso dissimulado da igualdade de oportunidades, reproduz e legitima diferenças. Bourdieu está se referindo às desigualdades de classes sociais, mas Britzman situa o problema na questão do racismo, ao sugerir "o conhecimento escolar como a corporificação das relações racializadas de poder"34, com base no trabalho de J. Ogbu ${ }^{35}$, enquanto Martin, Serbin, Swann e Swann e Graddol $^{36}$ mostram formas diversas pelas quais a escola orienta a sociabilidade de gênero segundo os padrões de inteligibilidade da matriz heterossexual. ${ }^{37}$

Ao passo em que o conflito na classe de aceleração se dá em questões raciais, estéticas (atreladas às raciais) e de gênero, o diálogo se dá na posição marginal no sistema no que se refere ao marcador do desempenho escolar. Na classe de aceleração, garotos brancos de classe média interagem com outros garotos brancos, mas de classe baixa, com garotas brancas de classe baixa e com garotas negras de classe baixa. No entanto, todos se encontram numa posição marginal na hierarquia institucionalizada do conhecimento. A sexualidade emerge no grupo dialogando com a questão da raça: ao passo em que os garotos brancos chamam Ana de "canhão" e outros adjetivos pejorativos, os garotos negros vivem em constantes "brincadeiras" sexuais com a

${ }^{33}$ BouRdieU, P. A escola conservadora... Op.cit.

${ }^{34}$ BritzMAn, D. P. O que é esta coisa chamada amor... Op. cit., p.72.

${ }^{35}$ OgBu, J. Class Stratification, Racial Stratification, and Schooling. In: WeIS, Lois. Class, Race, and Gender in American Education. Albany, Suny Press, 1988.

${ }^{36}$ MARTIN, K. A. Becoming a gendered body... Op. cit.; SERBIN, Lisa A. Teachers, peers and play... Op.cit.; SwANN, J. Girls, boys and language. Op. cit.; SwANN, J. e GRADOOL, David. Feminising classroom talk? In: Mills, Sara (ed.) Language and gender: interdisciplinary perspectives. London, Longman, 1995.

${ }^{37}$ ButLER, J. Gender Trouble... Op.cit. 
Marcadores sociais da diferença e infância

garota, como "passar a mão". A sexualidade de Ana, vista como perigosa pela diretora no que se refere ao contato da "préadolescente" com "crianças" de outras séries, é explorada pelos garotos brancos, atribuindo-lhe nomes pejorativos e através de comentários que sugerem promiscuidade: "Na resposta você ganha, na cama você arreganha" (Marcos, para Ana).

A situação na $4^{a}$ série $\mathrm{B}$ é bastante distinta, começando pelo fato de não haver o marcador de raça. As diferenças de classe existem, mas a maioria pertence à classe média. Todas as crianças estão "em fase" com a grade curricular. Além do gênero, quais seriam então os marcadores das diferenças?

A estética aparece como um marcador importante, mas longe da intenção de operar sozinho. A estética, neste caso, permanece atrelada à raça, pois, como coloca Frankenberg ${ }^{38}$, a raça não está apenas marcada no corpo, mas constitui um ponto de vista e, como sugerido a partir da noção de corporificação, percepções de mundo que terminam na objetificação do corpo.

Nossas vidas não são sempre vividas em corpos objetificados, pois nossos corpos não são originalmente objetos para nós. Eles são, ao contrário, o terreno de processos perceptivos que terminam na objetificação. ${ }^{39}$

$\mathrm{Na}$ estrutura das relações na $4^{\mathrm{a}}$ série não há diferenças raciais, mas cada criança ali presente carrega percepções negociadas e construídas em vários contextos (família, mídia, igreja etc.). Dessa forma, as crianças da $4^{\mathrm{a}} \mathrm{B}$, apesar da ausência visível de corpos marcados pela raça negra, têm percepções incorporadas sobre as diferenças de raça e os padrões estéticos a

\footnotetext{
${ }^{38}$ FRANKENBERG, R. Growing up white... Op. cit.

${ }^{39}$ CSORDAS, T. J. Introduction... Op.cit., p.7: "Our lives are not always lived in objectified bodies, for our bodies are not originally objects to us. They are instead the ground of perceptual processes that end in objectification (Merleau-Ponty 1962; Csordas 1990, 1993, 1994)".
} 
elas relacionadas e suas hierarquias de status social. Em outras palavras, o referencial é a beleza branca ocidental européia.

Nesse contexto, Bruna pode ser considerada uma amostra fiel. Branca, loura de olhos verdes e apresentando traços diacríticos fiéis ao modelo europeu, Bruna dispõe da admiração de sua beleza tanto por parte dos garotos quanto das garotas, assim como do professorado, dos funcionários e da diretoria. Popular na escola, poderíamos dizer que Bruna é a "musa" da escola, acirrando disputas entre garotos das $4^{\text {a }}$ s séries e ouvindo normalmente os garotos referirem-se a ela como "gostosa". Mas não podemos dizer que a beleza branca de Bruna é o que garante seu "sucesso". Numa classe em que todos são brancos, a beleza de Bruna se descola da raça apenas aparentemente. O fato é que a beleza da garota, entre os brancos, aproxima-se demais do "ideal" dos padrões europeus de estética. Mesmo entre os brancos, há uma hierarquia da estética, da correspondência mais longínqua à mais próxima dos contornos definidos pelo modelo europeu. Dessa forma, sugiro que os referenciais do racismo continuam operantes por detrás das aparências de "igualdade" entre os brancos. Além disso, outros fatores contribuem para "fazer a diferença" na $4^{a}$ série $\mathrm{B}$. Além das diferenças "internas" à raça, outras supostas "homogeneidades" são colocadas em questão. Apesar de todos serem considerados alunos "em fase", há uma hierarquia do conhecimento no interior da sala, assim como uma divisão de facções entre as garotas da sala e um espectro hierárquico de masculinidades entre os meninos. Assim como a raça, as diferenças de classe graças a uma minoria pobre também vão operar "por trás" das relações, em conjunto com os demais marcadores.

Reformulando a apresentação da $4^{\mathrm{a}} \mathrm{B}$, a classe divide-se entre "a turma da Bruna", as outras meninas da sala, o grupo dos garotos, Jonas, e, como intermediário entre Jonas e os garotos, seu colega Fábio. Bruna, uma das melhores alunas da sala, é constantemente elogiada pelos garotos por sua beleza e participa atentamente das aulas. Além disso, é conhecida por toda a escola, 
Marcadores sociais da diferença e infância

desde os funcionários da secretaria até as crianças da $1^{\text {a }}$ série. Segundo a professora Adriana, Bruna ainda é motivo de conflito entre as duas quartas séries, pois havia terminado o namoro com um garoto da $4^{a}$ A para iniciar um relacionamento com Diego, da sua classe. A turma da Bruna é composta pelas garotas "mais bonitas e mais inteligentes" da classe, segundo as crianças. Além disso, são as garotas da classe que começam a explorar sua sexualidade, principalmente através de um vestuário que visibiliza seus corpos (o que pude observar em ocasiões informais, como em festas, já que no cotidiano é obrigatório o uso de uniforme) e constituem-se como sexualmente desejadas pelos garotos. A preferência e o respeito das professoras e da diretoria por Bruna e suas amigas pode ser observado em inúmeras situações no cotidiano da escola. Quando a professora falta, por exemplo, as substitutas são instruídas pelas professoras da turma e pela secretaria, em caso de alguma dúvida sobre o conteúdo didático trabalhado ou a localização de algum material escolar, a "perguntar à Bruna". Além disso, a garota sempre lidera os eventos: organização de festas de aniversário, apresentações de dança, etc., sendo-lhe delegada total liberdade de ação por parte das professoras. Bruna não precisa pedir para sair da sala $e$ não ouve nenhuma repreensão se encontrada pelos corredores da escola. Para qualquer outra criança, essas atitudes seriam alvo de repressões por parte das professoras e da diretoria, em especial se fossem alunos da aceleração.

A professora Adriana se tornou responsável pela turma apenas no segundo semestre $e$, talvez por ter iniciado sua relação com uma dinâmica já constituída do grupo, pode visualizar e comentou comigo sobre todos esses indicadores referentes à Bruna, que eu já havia observado. Notei ainda que Bruna freqüentemente reproduzia discursos e comportamentos socialmente esperados dos adultos, como em suas atitudes de liderança, quando exigia "responsabilidade" e "disciplina" por parte das crianças ou quando interferia em brigas físicas entre os garotos na hora do intervalo, oferecendo "assistência à vítima". 
Devido à sua posição privilegiada na estrutura do grupo, a garota despertava a rivalidade das demais garotas da turma que procuravam formar um grupo em "oposição" à Bruna e que interagisse com a turma de Bruna apenas no que fosse necessário. O grupo dessas garotas compunha um espectro de garotas freqüentemente ridicularizadas pelos meninos, por questões estéticas ou de desempenho escolar. Adjetivos como "burra", "feia" e "chata" eram comuns por parte dos garotos ao se referirem a elas, ao mesmo tempo em que eles sequer pensavam em imaginá-las como possíveis "namoradas", o que ocorria apenas com a turma da Bruna. Márcio: "Camila, abaixa a cabeça!" (para que ele pudesse ler à lousa). Henrique: "Chama de feia que ela entende". Além disso, essas garotas ainda compunham um grupo marginalizado pelas professoras no que se referia a desempenho escolar, já que não eram "alunas exemplares" como Bruna e suas colegas.

Segundo a professora Adriana, as colegas de Bruna não tinham "a mínima personalidade", submetendo-se a todas as regras definidas pela garota, com exceção de Vanessa. O lugar de privilégio de Bruna instigava uma rivalidade interna entre ela $e$ Vanessa, uma oposição que começava em termos físicos, sentando-se em fileiras diferentes (as demais sentavam-se à frente $e$ atrás de Bruna), mas estendia-se à rivalidades intelectuais, estéticas e de sexualidade, no que se referia ao desejo dos garotos. No que se refere ao grupo das outras garotas, as diferenças de performance escolar e preferências pessoais por brincadeiras $e$ atividades formavam um espectro bastante amplo, desde Isabel, que se dedicava a escrever inúmeros "versos" sobre o amor romântico, até Patrícia, que geralmente travava discussões com os garotos sobre computadores e vídeo-games.

Da mesma forma que não conseguimos visualizar um grupo homogêneo de garotas, dada a diversidade de posturas, comportamentos, atitudes e preferências entre elas, os garotos também apresentam uma fragmentação enquanto "grupo", marcada por questões como desempenho escolar e 
Marcadores sociais da diferença e infância

masculinidade. Diego, por exemplo, era respeitado pelos garotos por dois motivos básicos: o status de ser o namorado de Bruna e seu desempenho exemplar nos esportes. O status de Diego por seu namoro com Bruna, embora relacionado ao status de Bruna nas relações do grupo, não pode ser visto como decorrente deste, já que ganha outros significados nas suas relações com os garotos. Namorar a garota mais "popular" da escola e mais desejada pelos meninos é uma forma de afirmar sua sexualidade heteronormativa e sua masculinidade entre seus colegas, aliada a seu desempenho viril nos esportes. Em sua pesquisa sobre adolescentes escoceses, Wight ${ }^{40}$ escreve que "meninas são primariamente valorizadas pelos garotos por seu respeito ganho dos pares masculinos" 41 , sendo que os garotos declararam manter pouco envolvimento afetivo com suas namoradas, preferindo geralmente a companhia masculina de seus amigos.

Os mesmos marcadores de sexualidade e esportes definem para os garotos a sexualidade de Jonas e Fábio, mas de forma inversa. A falta de interesse, declarada, de Jonas pelo futebol e pelos esportes em geral provocava comentários marginalizantes de outros garotos, classificando-o como "bicha" e "gay". Da mesma forma, Fábio foi estigmatizado quando se recusou a ver um anúncio sobre lingerie que um garoto queria lhe mostrar: "Ô seu gay, nem mulher pelada cê quer ver?!". Nos conflitos entre Fábio e Jonas, o primeiro utiliza-se dos mesmos termos pejorativos referentes à sexualidade: "Ô seu veado, derrubando minhas coisas?!"

Jonas era constantemente marginalizado pelos garotos.

Leandro: Jonas, fala que você gosta de boneca, fala! [em seguida] Vou assistir sua peça de balé lá no teatro! João: Ele dorme com um monte de bonequinhas!"

${ }^{40}$ WIGTH, Daniel. Boys' thoughts and talk about sex in a working class locality of Glasgow. The sociological review, vol. 42, n 4, nov./1994, pp.703-737.

${ }^{41}$ ID., IB., p.712: "girlfriends are primarily valued by boys for the esteem gained from male peers". 
Érica Renata de Souza

[Nesse momento] Henrique, para João: Cala a boca que você é outro gay, não sabe nem chutar [referindo-se ao futebol]

Leandro [novamente, para Jonas]: Jonas, cê gosta de bonequinha, né?

[Outro garoto] Você é um gay!

Leandro: Vou dar um ursinho carinhoso pra você!

Jonas, além de declarar seu desinteresse pelos esportes, não interagia com os outros garotos em hipótese alguma, sentava-se apenas entre as garotas e dialogava somente com algumas delas, as que se sentavam próximas a ele. Fábio era o único garoto com quem Jonas interagia, mas Fábio também não deixava de ser estigmatizado. Na divisão da classe para trabalhos em grupo, Fábio aproximava-se dos garotos quando Henrique lhe disse: "Aqui é só homem, ô!" Fábio: "É? E eu sou o quê?" Henrique: "Bicha!". Fábio então limitou-se a olhar para o garoto com desdém. A posição de Fábio na hierarquia das masculinidades era visivelmente intermediária. Fábio sentava-se ao lado de Jonas, mas levantava-se freqüentemente para conversar com os outros meninos. Praticamente ignorava a marginalização dos garotos sobre sua masculinidade e tentava constantes diálogos e aproximações, mas jamais abandonava Jonas e também interagia com as garotas com as quais Jonas dialogava. Algumas vezes notei alguns garotos levantarem-se e dirigirem-se até a carteira de Fábio para conversarem, mas sempre ignorando Jonas, ao lado. Notei ainda que, apesar de interagir tanto com os meninos quanto com as meninas, Fábio sustentava posturas diferentes de acordo com o gênero de seu interlocutor. Ao conversar com as garotas, apresentava-se sempre calmo, sentado. Quando dirigia-se aos meninos, ficava em pé, balançava o corpo e verbalizava rapidamente. Além disso, Fábio não somente respondia às agressões verbais dos garotos como também chegou a se envolver em brigas físicas, enquanto Jonas limitava-se a ignorar qualquer comentário, sem sequer olhar para o enunciador. Observei apenas uma vez Jonas reagindo, começando a brigar fisicamente com 
Marcadores sociais da diferença e infância

Tiago, o que provocou um comentário irônico por parte de Henrique: "O que é isso? Tá querendo virar homem?". Num dia em que Fábio faltou, durante a chamada, quando a professora chamou pelo garoto, Jonas respondeu que ele havia faltado. Nesse momento, Bruno disse, ironicamente: "É a mulher dele que responde!", dirigindo o olhar para Jonas, que não reagiu.

Em suma, Jonas não corresponde às várias expectativas associadas socialmente aos homens. Pelo contrário, demonstra em sala de aula características que a inteligibilidade da matriz heterossexual traduz como femininas: passivo, pudico, mantém amizades com garotas, evita a sociabilidade com os meninos, não gosta de esportes... No entanto, estas características parecem ser uma performance situada na sala de aula. Numa entrevista com a mãe de Jonas, esta revelou que, em casa e nas relações com os amigos do bairro e parentes da mesma idade, o garoto é superativo fisica e verbalmente e mantém relações amistosas com ambos os gêneros. Segundo ela, Jonas contou-lhe que os garotos de sua classe tentaram obrigá-lo a ver revistas pornográficas, mas ele se recusou, atitude com a qual a mãe concordou integralmente. A mãe de Jonas me disse que ele é um garoto totalmente "normal", ativo, interativo com seus amigos, mas sempre "dentro dos limites permitidos por Deus". A família de Jonas é protestante e sua mãe declarou inclusive "selecionar" os programas de televisão que seus filhos assistem.

Segundo a pesquisa de Levitt ${ }^{42}$ sobre socialização religiosa, o Cristianismo é puerilizado, ou melhor, centrado nas crianças, nos pré-adolescentes e nas mães, especialmente os rituais. Nesse sentido, Levitt escreve que as mães procuram oferecer aos filhos experiências religiosas que acreditam fazer parte de uma "infância normal". Da mesma forma, sugiro, procuram controlar o acesso

${ }^{42}$ LEVITT, Mairi. Sexual identity and religious socialization. The British journal of sociology, vol. 46, n 3, sep./1995, pp.529-536. 
das crianças às experiências que consideram "anormais", a partir da crença cristã na pureza e na inocência infantis. ${ }^{43}$

Daí entendermos as posturas performáticas do garoto $e$ diferenciadas em casa e na escola. Em casa, Jonas se adequa perfeitamente às expectativas religiosas para uma "criança", enquanto, na escola, é esperada dele uma postura de "homem", de virilidade diante de um padrão hegemônico de masculinidade. No conflito entre as expectativas da escola, da família e da igreja, Jonas se distancia do grupo que exige dele uma masculinidade associada à sexualidade, esta controlada e reprimida pela família e pela igreja. Dada uma provável supremacia dos valores da família e da igreja para Jonas, na escola, o garoto se cala e se distancia dentro de uma estrutura estruturante da sexualidade onde não há lugar para seus valores, sendo excluído e se auto-excluindo. Em outras palavras, a performance de gênero de Jonas nas relações em sala de aula não satisfaz a noção de masculinidade "utilizada para celebrar e reforçar a masculinidade normativa". ${ }^{44}$

Utilizo a noção de performance no caso de Jonas no sentido de que

atributos e comportamentos convencionalmente associados à "masculinidade" ou "feminilidade" podem ser seletivamente afirmados para marcar um indivíduo tanto como "macho" quanto como "fêmea", enquanto as

\footnotetext{
${ }^{43}$ GagneBIN, J. M. Infância e Pensamento. In: Sete aulas sobre linguagem, memória e história. Rio de Janeiro, Imago, 1997.

${ }^{44}$ CoRnWAll, Andrea e Lindisfarne, Nancy. Dslocating masculinity: gender, power and anthropology. In: CoRnwall, A. e LiNDISFARNE, N. (eds.) Dislocating masculinity: comparative ethnographies. London, Routledge, 1994, p.12 (grifos meus): "used to celebrate and enhance normative maleness". Assim como Cornwall e Lindisfarne, Miguel Vale de Almeida trabalha com a noção de "masculinidade hegemônica", no sentido de um "modelo central que subordina as masculinidades alternativas (...), e que é o modelo da dominação masculina, intrinsecamente monogâmica, heterossexual e reprodutiva". VALE DE ALMEIDA, M. Leitura de um livro de leitura... Op. cit., p.16
} 
Marcadores sociais da diferença e infância

fronteiras entre ambos são constantemente renegociadas $e$ redesenhadas em cada encontro. ${ }^{45}$

Vimos que as intervenções marginalizantes sobre Jonas vieram, sobretudo, da parte de Leandro. Este garoto, bastante obeso, apesar do gosto declarado pelo futebol, não se constitui como nenhum "exemplo" na prática de esportes, como Diego. Não se envolve em conflitos corporais nem apresentou namorada alguma aos colegas. É uma das raras crianças da $4^{a} \mathrm{~B}$ que moram naqueles bairros estigmatizados pela violência $e$ alto índice de criminalidade. Mas Jonas não era o único "alvo" de Leandro, que freqüentemente ridicularizava seus colegas, de alguma maneira, como ao chamar João de "caipira" e "roceiro", ao se referir à região de origem do garoto.

Se tomássemos por referência apenas a configuração de marcadores acima, Leandro não disporia de um lugar privilegiado na hierarquia de poder da sala de aula. No entanto, embora esteja sempre ridicularizando seus colegas, o respeito e a admiração destes por Leandro é bastante visível. Os garotos geralmente pedem-lhe conselhos e opiniões, mostram-lhe objetos pessoais, solicitam sua participação nas atividades... Esse status de Leandro parece ser resultante de apenas um fator, mas um fator que ganha grandes proporções na hierarquia de poder na sala de aula: seu sucesso acadêmico. Da mesma forma que Bruna e suas colegas monopolizam as melhores notas e desempenho nas atividades escolares, Leandro, por sua vez, é o único garoto que se encontra no mesmo nível de desempenho que as meninas, o que parece garantir-lhe uma posição privilegiada nas relações de poder entre os garotos. Como sugere Wight ${ }^{46}$, os garotos preferem a

${ }^{45}$ CoRnWAll, A. e Lindisfarne, N. Dislocating masculinity... Op.cit., p.17: "attributes and behaviour conventionally associated with 'masculinity' or 'femininity' can be selectively asserted to mark a single individual as both 'male' and 'female', while the boundaries between the two are constantly renegotiated and redrawn in each encounter"

${ }^{46}$ WiGTH, D. Boys' thoughts and talk about sex... Op. cit. 
sociabilidade masculina (ou a homossocialidade, nos termos de Vale de Almeida ${ }^{47}$ ) e se preocupam em reforçar sua auto-estima entre seus colegas através de suas namoradas, a investigação de Nilan também revela que

os meninos tendem a ficar mais preocupados em estabelecer suas reivindicações de masculinidade aos olhos dos outros meninos assim como em estabelecer superioridade em relação às meninas. ${ }^{48}$

O caso de Leandro, no entanto, revela um marcador de privilégio na hierarquia não relacionado à sexualidade. $\mathrm{O}$ lugar privilegiado de Leandro, mesmo não dispondo de atributos socialmente tidos como símbolos da masculinidade, como força e desempenho nos esportes, nem os demais "predicados" que garantiam o status de Bruna nas relações da sala de aula, é facilmente compreendido ao situarmos as relações na instituição escolar, onde a performance acadêmica é o marcador primário nas relações de poder da instituição, seja entre as crianças ou entre as crianças e os adultos (professores, diretoria, pais, etc.). E apesar ainda de seu local de residência estigmatizado e de sua obesidade (que às vezes gerava brincadeiras por parte dos garotos, mas sempre numa conotação "amistosa"), mantinha-se extremamente respeitado por seus colegas.

Segundo Cornwall \& Lindisfarne, "as pessoas negociam relativas posições de poder como indivíduos e como representantes de uma categoria social como aquelas baseadas em gênero, idade, classe ou etnicidade". ${ }^{49}$

\footnotetext{
${ }^{47}$ VALE DE ALMEIDA, Miguel. Senhores de si: uma interpretação antropológica da masculinidade. Lisboa, Fim de Século, 1995.

${ }^{48}$ NiLAN, P. Negotiating gendered... Op. cit., p.28: " boys are likely to be as much preoccupied with establishing their claims to masculinity in the eyes of other boys as they are with establishing superiority over individual girls".

${ }^{49}$ CoRnWAll, A. e Lindisfarne, N. Dislocating masculinity... Op.cit., p.15: "(P)eople negotiate relative positions of power as individuals and as
} 
Marcadores sociais da diferença e infância

Se Diego e Jonas são exemplos do modo com que o gênero determina posições na hierarquia de poder entre os garotos, o caso de Leandro não somente ajuda a perceber que outros marcadores estão em jogo nessas relações de poder, como também se contrapõe à teoria do "privilégio cultural" postulada por Bourdieu, segundo a qual o background cultural familiar, estreitamente relacionado à classe social, favorece as classes privilegiadas com uma aprendizagem distinta da educação formal oferecida pela escola. Em outras palavras, as classes sociais e o ethos de classe definiriam capitais culturais incorporados, distintos e assimétricos em termos de valor social e de status, constituindo um mecanismo de superseleção que determinaria o fracasso escolar e a exclusão dos alunos das classes desfavorecidas. ${ }^{50}$

Sugiro, portanto, que a visibilidade e a importância dos marcadores sociais é algo dado situacionalmente, incorporados nas relações entre o subjetivo e coletivo, de acordo com as exigências da instituição, do grupo social e do contexto em que os sujeitos estão inseridos, ou seja, de acordo com a configuração de marcadores sociais específica de cada grupo.

As crianças, a matriz heterossexual $e$ a heteronormatividade $e^{51}$

\section{Segundo Britzman}

a identidade sexual está sendo constantemente rearranjada, desestabilizada e desfeita pelas complexidades da

representatives of social categories such as those based on gender, age, class or ethnicity."

${ }^{50}$ No entanto, na concepção de Bourdieu, Leandro representaria apenas uma das "exceções" (em termos de classe social desfavorecida) cujo sucesso acadêmico favoreceria a sustentação do mito da escola libertadora, através do discurso do "dom natural". BOURDIEU, P. A escola conservadora... Op. cit.

${ }^{51}$ BRITZMAN, D. P. O que é esta coisa chamada amor... Op. cit., p.79. Heteronormatividade, segundo Michael Warner, seria "a obsessão com a sexualidade normatizante, através de discursos que descrevem a situação homossexual como desviante." 
experiência vivida, pela cultura popular, pelo conhecimento escolar e pelas múltiplas e mutáveis histórias de marcadores sociais como gênero, raça, geração, nacionalidade, aparência física e estilo popular. ${ }^{52}$

De acordo com o diretor da escola (posteriormente substituído por Cecília, até então vice-diretora), em conversa informal, o currículo está mudando, distanciando-se dos estereótipos e atendendo à necessidade de se adaptar às mudanças perceptíveis pelas crianças nas estruturas familiares, oferecendo o exemplo de pais que realizam o trabalho doméstico, ou seja, exemplificando com mudanças nas relações de gênero no âmbito doméstico.

No entanto, nos materiais didáticos utilizados pelas professoras e pela escola não identifiquei qualquer tentativa de problematizar o gênero ou a questão da família. Mas vimos na relação das professoras com os marcadores sociais em que medida estas, individualmente, reproduzem certos estereótipos $e$ rejeitam outros, de forma situacional. As orientações de gênero no sentido da matriz heterossexual se dão informalmente no cotidiano das aulas, considerando ainda que na escola não havia aulas de educação sexual. Como bem coloca Britzman ${ }^{53}$, o conhecimento formal sobre sexualidade em sala de aula (quando há), corresponde a uma transmissão estrita de informações sobre heterossexualidade reprodutiva.

Essa sugestão de Britzman remete a um episódio na classe de aceleração. Certa vez, fixados nas paredes da classe, havia vários trabalhos de colagem da turma de aceleração da tarde. Num desses cartazes figuravam duas mulheres se beijando. Quando percebi Maria e Luís observando o trabalho, aproximeime e ouvi os respectivos comentários: "Ai, credo!" e "Sai fora!". Aproveitei o momento e pedi uma justificativa à garota, que então

\footnotetext{
52 ID., IB., pp.74-75.

53 ID., IB.
} 
Marcadores sociais da diferença e infância

completou que "achava chato mulher com mulher" porque "se você gosta de alguém, você tem vontade de fazer outra coisa e aí elas não podem...". Maria, aos onze anos, não consegue conceber uma relação sexual entre o mesmo gênero ou o mesmo sexo (já que nos padrões de inteligibilidade heterossexuais da garota sexo e gênero são análogos), pois "sexo", em sua concepção, corresponde a uma relação entre pessoas dual e biologicamente opostas, onde haja a possibilidade de reprodução.

Alessandro apresentou reação semelhante. Ao me mostrar a foto e ouvir meu comentário "O que é que tem?", respondeu: "Credo! Tem que ela devia estar beijando um homem e não outra mulher!" Como Maria e Alessandro, a reação de Márcio revela como as crianças se pautam na "naturalidade" da coerência imposta pela matriz heterossexual a fim de assegurarem a inteligibilidade das informações. Márcio se aproxima do cartaz e diz: "Essa é o homem e essa é a mulher".

A foto, denotando elementos homossexuais, exposta na parede da sala de aula, envolve ainda outros aspectos: a professora da turma responsável pelo aluno que realizou o trabalho não parece ter se incomodado com a informação heterodoxa que a imagem carregava, $e$ a professora da aceleração da manhã, Vera, surpreendeu-se com a imagem, mas nada comentou com os alunos ou explorou o assunto. A informação parecia estar fixada e exposta na parede como uma "inevitável parte da realidade do mundo", mas estranha às concepções e expectativas daquele grupo. Já o motivo pelo qual o aluno responsável pelo trabalho recortou esta imagem de uma revista, quando o trabalho de colagem parecia ter uma proposta "livre", talvez possa ser parcialmente compreendido diante das "novas formas de visibilidade $e$ de acesso aos códigos culturais homossexuais para o consumo de massa". ${ }^{54}$

Assim como para Alessandro uma das garotas que se beijavam devia ser "o homem", Regiane, em outro momento, me

${ }^{54}$ ID., IB., p. 75. 
disse que não gostava de "travestis", apontando para a foto. Uma das garotas era bastante andrógina, mas sua aparência mostravase distante de qualquer semelhança a um travesti. Em outro momento da pesquisa, Marcelo também sugeriu que "quem usa [roupa] rosa é veado, travesti". A distinção entre as concepções de travestis, drag queens, transgêneros, gays e lésbicas é algo obscuro à inteligibilidade heterossexual e heterossexista ${ }^{55}$ que exige uma linearidade normativa entre sexo, performance de gênero $e$ sexualidade:

Essa confusão entre gênero e sexualidade parece ser mais notada quando, por qualquer razão, certos corpos não podem ser 'lidos' e fixados como mais uma confirmação dos discursos da universalidade e da natureza. ${ }^{56}$

Se, como sugere Sedgwick, as ignorâncias "são produzidas por conhecimentos particulares, correspondem a conhecimentos particulares e circulam como parte de regimes particulares de verdade" ${ }^{57}$, sugiro que a preservação dessa ignorância sobre a pluralidade que o gênero e a sexualidade envolvem é uma das formas de reprodução da matriz heterossexual. E, como sugere Britzman, num "efeito espelho", a ignorância sobre a homossexualidade corresponde à ignorância do processo de construção social da heterossexualidade.

Dentro dessa lógica, percebemos um movimento semelhante dentro da hierarquia das masculinidades, tanto entre os garotos da aceleração quanto da $4^{\mathrm{a}} \mathrm{B}$, onde o discurso heteronormativo opera com adjetivos pejorativos como "bicha", "boiola", "veado", etc., numa conotação, segundo sua inteligibilidade, de "feminização", ou seja, legitimando uma

${ }^{55}$ Sugiro a noção de "heterossexismo" numa conotação homofóbica, constituindo-se como um preconceito produzido a partir do conceito de "heteronormatividade".

${ }^{56}$ BRITZMAN, D. P. O que é esta coisa chamada amor... Op. cit., p.76.

${ }^{57}$ apud ID., IB., p.91. 
Marcadores sociais da diferença e infância

possível reconfiguração de sexo e gênero de forma desviante $e$ colocando o garoto "feminizado" (mesmo que em performances situacionais) numa posição marginal $e$ desprivilegiada da hierarquia.

O modo com o qual a linguagem opera a favor da normatividade é amplamente percebido no caso de Ana, chamada de "Canhão" (referente à estética), "Bombril", "Cabelo de vassoura" (raça) e "Sargento". Quanto à "sargento", não consegui obter sequer uma justificativa por parte das crianças, mas acredito estar negativamente associado à postura exacerbadamente agressiva de Ana, o que a "masculinizaria". Estigmatizada no olhar racializado dos garotos brancos, Ana ainda se torna alvo de chacota devido a um comportamento que transgride a matriz heterossexual. Mas, novamente, a reconfiguração do sexo e do gênero ganha um caráter de desvalorização. Através de um gênero masculinizado ${ }^{58}$ que não corresponde à linearidade esperada pela matriz heterossexual e na relação com outros marcadores sociais "desprivilegiados", Ana tem garantido o "direito" a uma posição inferiorizada nas relações de poder produzidas no interior do grupo.

As concepções de raça são percebidas por Ana (através de um processo de produção e reprodução na interação com os outros) num corpo "irreversivelmente marcado". Diante desse fato $e$ de sua situação desprivilegiada de classe, sugiro que, se a obediência às normas da matriz heterossexual se apresenta como um critério para a aceitação social, talvez possamos entender o que "facilitou" que Vera obtivesse resultados, ao menos contextuais, em seu "projeto de feminização" de Ana e das garotas da aceleração. Mas não nos esqueçamos que, mesmo no interior da heteronormatividade, Ana é criticada pelos garotos no sentido da perversão. Além de chamá-la de "quenga" (prostituta),

\footnotetext{
58 Utilizo o termo "masculinizado" ao invés de "masculino" no intuito de sugerir que não ocorre um processo de "assimilação", mas de seleção e ressignificação de elementos do gênero masculino.
} 
Érica Renata de Souza

os garotos costumam fazer comentários como "A Ana fica na esquina" (Marcelo) e outros vistos anteriormente. E lembremos da preocupação da diretora a respeito da sexualidade "ameaçadora" de Ana no contato com os "pequenos inocentes".

Nesse sentido, concluo com a sugestão de Britzman:

A "criança" de qualquer pedagogia já está, ao mesmo tempo, codificada como uma criança generificada [gendered], sexuada e racializada. Nesse sentido, a "criança" se torna um dos constructos mais normalizados e regulados da educação. ${ }^{59}$

${ }^{59}$ BRITZMAN, D. P. O que é esta coisa chamada amor... Op. cit., p.78. 